\title{
An Actual Verification and Comparative Experiment on Fabric Defects Automatic Detection System
}

\author{
Jie Song ${ }^{1, a}$, Qing Song ${ }^{2, b}$, Shuping Yin ${ }^{3, c}$, Ya-na Zhang ${ }^{4, d}$ \\ ${ }^{1,3,4}$ Department of Software Engineering Shijiazhuang Information Engineering Vocational \\ College ,Shijiazhuang, China \\ ${ }^{2}$ School of Foreign Languages Kunming University ,Kunming, China \\ asong_jie@126.com, ${ }^{\text {b songqing9@163.com, }{ }^{c} 947383963 @ q q . c o m,{ }^{d} z y n z y m 105 @ s i n a . c o m ~}$
}

Keywords: fabric; defects; detection; experiment

\begin{abstract}
This paper presents a fabric defects automatic detection system which uses firstly local entropy to detect roughly and then single adaptive wavelet analysis, finely, and reports an actual verification and comparative experiment. The experimental results verify the feasibility and effectiveness of this system. To seek the effective algorithm of all fabric defects detection, this experiment conducted a meaningful exploration and bold try.
\end{abstract}

\section{Introduction}

With increasing loom speed continuously, the output of fabric has been increased quickly. But the fabric defects detection, namely perching, which is the key link of quality control, is still based on artificial visual detection, in which many disadvantages are present, such as low speed, high un- and error-detected rate, heavy labor intensity and the great influence of personal factors, etc. It has become a "bottleneck" in the continuous and large-scale production of textile, which has seriously restricted the further development of textile industry. For this reason from 1970s, many researchers at home and abroad started to research fabric defeats automatic detection, many research results have been produced. Commercial systems have been produced abroad, but they are inapplicable to the actual situations of domestic enterprises and difficult to satisfy their actual needs. But mature products do not come out at home and are still in a theoretical research stage.

China is a main country of textile, its market demand for fabric defects automatic detection is great. So in the experiment based on the experiences and lessons summed up by our predecessors, various efficient methods were combined, domestic enterprises reality was considered, and new ideas were brought forth in the system design. In view of the actual situation that fabric defects rate is generally less than 5\%, it was necessary to design an automatic detection system which speed is high, cost low and stability good. So a design alternative of firstly rough detecting then fine detecting, that is, the fabric defects automatic detection system based on machine vision was put forward. And a detailed design, an actual verification and a comparative experiment were made. This system is realized by adopting MSSQL server 2005, PowerBuilder 11.

In this design, first local entropy is used to detect fabric defects in rough. The fabric images pretreated equally with their histograms are divided into the same size windows. The local entropy of each window is calculated. The windows which local entropy is smaller are chosen as the interesting areas that may have defects, and then will be finely detected. On the contrary, the windows which local entropy is bigger are normal fabric's ones, which images aren't preserved. On the one hand, this can increase the speed of processing images; on the other hand, it can lower the demand on software and hardware, and lay a good foundation for lowering the cost of the system. Next, in a fine detecting stage, a single adaptive wavelet analysis is used to decompose the images of normal fabric. $\mathrm{HH}$ sub-image that contains less information is eliminated, and the standard deviations and ranges of other three sub-images are calculated to get a detection basis[1]. Finally the images of the interesting areas are decomposed and the standard deviations and ranges of the three sub-images are calculated, which are compared with the detection basis, and their deviations are calculated out. If the sum of 
these deviations is bigger than a fixed threshold, it would be confirmed that defects are present in the images. [2,3]

The following is an introduction to an actual verification and a comparative experiment of the design alternative.

\section{Actual Verification}

Experimental Procedures. The pure cotton grey cloth produced by Shijiazhuang No.2 Cotton Textile Branch Company was used as an object of research in this experiment. The fabric defects automatic detection flow chart as shown on Fig. 1.

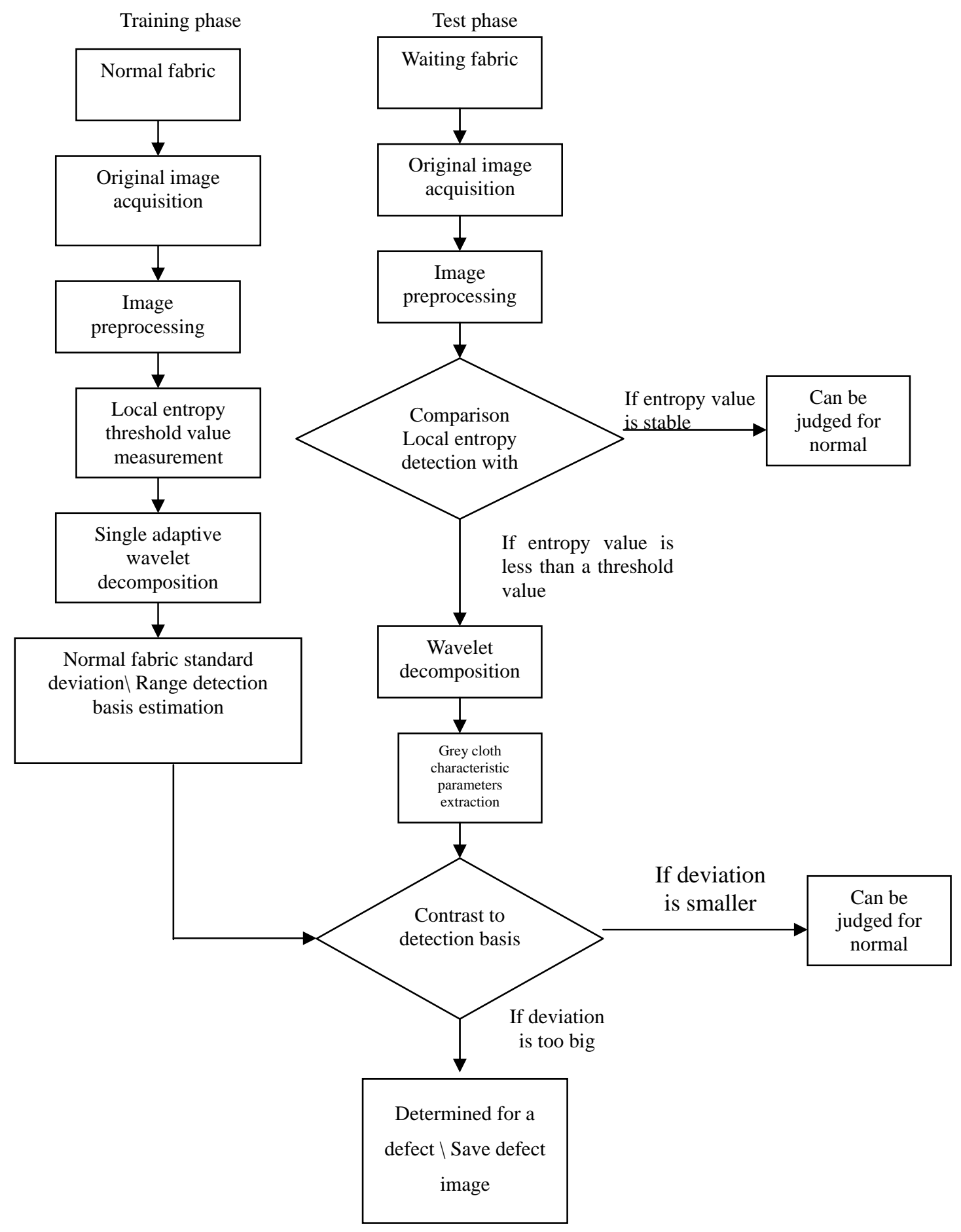

Figure1. The implementation flow chart of the fabric defects automatic detection system 
Experimental process, results and discussion.Pure cotton grey cloth was used in the experiment. First 20 defect-free images were collected as samples and then pretreated. Finally a local entropy threshold $\mathrm{H}_{\mathrm{k}}$ was measured out.

Registered users can be allowed to access the system. To ensure safety in detection data, the users of different ranks use different passwords to access the system, and enjoy different competence.

Table 1 Normal fabric local entropy detection data

\begin{tabular}{|c|c|c|c|c|c|c|c|c|c|c|}
\hline $\mathrm{k}$ & 1 & 2 & 3 & 4 & 5 & 6 & 7 & 8 & 9 & 10 \\
\hline $\mathrm{H}$ & 0.8712 & 0.8235 & 0.8621 & 0.8213 & 0.8715 & 0.8234 & 0.8421 & 0.8239 & 0.8125 & 0.8367 \\
\hline $\mathrm{k}$ & 11 & 12 & 13 & 14 & 15 & 16 & 17 & 18 & 19 & 20 \\
\hline $\mathrm{H}$ & 0.8264 & 0.8127 & 0.8361 & 0.8243 & 0.8641 & 0.8234 & 0.8624 & 0.8143 & 0.8224 & 0.8346 \\
\hline
\end{tabular}

In order to accurately determine the minimum entropy detection threshold, several kinds of common defects were chosen as sample, which local entropy was detected to determine the final threshold. By contrasting the detection data, it is known that 0.8 was chosen for local entropy detection threshold $\mathrm{H}_{\mathrm{k}}$. All the local entropy of images awaiting detection was compared with the threshold. If local entropy is bigger than the threshold, the fabric would not contain defects, no longer its image is further decomposed on wavelet; if smaller, the image would be listed as an interesting area, further processed.

Table 2 Defects fabric local entropy detection data

\begin{tabular}{|c|c|c|c|c|c|c|c|c|}
\hline $\begin{array}{c}\text { defect } \\
\text { sample }\end{array}$ & $\begin{array}{c}\text { broken } \\
\text { ends }\end{array}$ & crapand & $\begin{array}{c}\text { double } \\
\text { end }\end{array}$ & $\begin{array}{c}\text { double } \\
\text { weft }\end{array}$ & $\begin{array}{c}\text { necked } \\
\text { yarn }\end{array}$ & flush & knees & $\begin{array}{c}\text { weft } \\
\text { crackiness }\end{array}$ \\
\hline 1 & 0.766 & 0.723 & 0.652 & 0.633 & 0.712 & 0.731 & 0.521 & 0.421 \\
\hline 2 & 0.765 & 0.742 & 0.631 & 0.624 & 0.732 & 0.725 & 0.511 & 0.498 \\
\hline 3 & 0.712 & 0.722 & 0.623 & 0.623 & 0.736 & 0.731 & 0.491 & 0.511 \\
\hline 4 & 0.731 & 0.721 & 0.643 & 0.635 & 0.728 & 0.726 & 0.533 & 0.536 \\
\hline 5 & 0.743 & 0.721 & 0.618 & 0.618 & 0.716 & 0.728 & 0.481 & 0.524 \\
\hline 6 & 0.721 & 0.736 & 0.623 & 0.631 & 0.724 & 0.765 & 0.532 & 0.513 \\
\hline 7 & 0.713 & 0.723 & 0.631 & 0.612 & 0.731 & 0.713 & 0.588 & 0.516 \\
\hline 8 & 0.761 & 0.712 & 0.614 & 0.621 & 0.722 & 0.719 & 0.521 & 0.563 \\
\hline 9 & 0.745 & 0.736 & 0.624 & 0.611 & 0.731 & 0.734 & 0.531 & 0.521 \\
\hline 10 & 0.733 & 0.725 & 0.635 & 0.634 & 0.714 & 0.721 & 0.562 & 0.524 \\
\hline Average value & 0.739 & 0.7261 & 0.6294 & 0.6242 & 0.7246 & 0.7293 & 0.5271 & 0.5127 \\
\hline
\end{tabular}

The twenty preprocessed defect-free images were decomposed on wavelet, and the standard-deviations and ranges of the three sub-images were calculated to get a detection basis:

Table 3 The standard deviations and ranges of normal fabric three sub-images

\begin{tabular}{|c|c|c|c|c|c|c|c|}
\hline $\begin{array}{r}\text { sub- } \\
\text { image }\end{array}$ & \multicolumn{2}{|c|}{ LL } & \multicolumn{2}{c|}{ LH } & \multicolumn{2}{r|}{ HL } & $\begin{array}{c}\text { three } \\
\text { sub-images }\end{array}$ \\
\cline { 2 - 8 } number & SD & MD & SD & MD & SD & MD & SD+MD \\
\hline 1 & 10.3 & 58.6 & 3.2 & 22.6 & 2.1 & 13.6 & 110.4 \\
\hline 2 & 10.5 & 52.6 & 3.9 & 23.1 & 2.2 & 12.1 & 104.4 \\
\hline 3 & 10.2 & 53.1 & 3.6 & 22.7 & 2.1 & 13.2 & 104.9 \\
\hline 4 & 10.6 & 56.8 & 3.5 & 23.4 & 2.6 & 11.9 & 108.8 \\
\hline 5 & 10.1 & 59.4 & 3.7 & 22.8 & 2.6 & 12.2 & 110.8 \\
\hline 6 & 10.1 & 61.2 & 3.2 & 24.1 & 3.1 & 11.8 & 113.5 \\
\hline 7 & 10.2 & 60.1 & 3.9 & 23.5 & 2.8 & 13.4 & 113.9 \\
\hline 8 & 10.6 & 58.5 & 3.1 & 24.3 & 2.4 & 12.9 & 111.8 \\
\hline 9 & 10.6 & 59.1 & 3.5 & 24.3 & 2.1 & 11.7 & 111.3 \\
\hline 10 & 10.2 & 56.4 & 3.6 & 23.1 & 2.4 & 13.6 & 109.3 \\
\hline 11 & 10.6 & 58.3 & 3.5 & 22.6 & 2.4 & 12.5 & 109.9 \\
\hline
\end{tabular}




\begin{tabular}{|c|c|c|c|c|c|c|c|}
\hline 12 & 10.1 & 60.2 & 3.5 & 22.8 & 2.3 & 11.4 & 110.3 \\
\hline 13 & 10.1 & 58.6 & 3.2 & 23.1 & 2.5 & 13.2 & 110.7 \\
\hline 14 & 10.5 & 56.8 & 3.6 & 24.1 & 2.9 & 12.3 & 110.2 \\
\hline 15 & 10.2 & 55.2 & 3.5 & 22.6 & 3.1 & 13.5 & 108.1 \\
\hline 16 & 10.2 & 58.3 & 3.4 & 23.1 & 2.7 & 12.5 & 110.2 \\
\hline 17 & 10.5 & 55.4 & 3.8 & 22.8 & 2.5 & 13.5 & 108.5 \\
\hline 18 & 10.3 & 59.3 & 3.9 & 22.8 & 2.2 & 11.8 & 110.3 \\
\hline 19 & 10.1 & 57.2 & 3.8 & 23.4 & 2.3 & 12.3 & 109.1 \\
\hline 20 & 10.3 & 54.1 & 3.3 & 23.6 & 2.4 & 12.1 & 105.8 \\
\hline Average value & 10.315 & 57.46 & 3.535 & 23.24 & 2.485 & 12.575 & 109.61 \\
\hline
\end{tabular}

Because the (SD+MD) data of the images in above table were compared with the Mean 109.61 to get the maximum deviation $4.8 \%$, standard deviation 5\% was chosen temporarily. In order to use the standard deviation to detect defects accurately - neither un- detect nor error-detect, the images known to contain defects were decomposed on wavelet, and the (SD+MD) of the three sub-images was calculated. The defects that appear more frequently were chosen, which mainly include the defects such as broken ends, crapand, double end, double weft, necked yarn, flush, knees and weft crackiness, etc. According to the above method, the standard deviation and range of LL, LH, HL sub-image was calculated respectively, which results were shown in the above table, thus the standard deviation was confirmed. [4,5]

Table 4 Standard deviations and ranges of distinct defects fabric

\begin{tabular}{|c|c|c|c|c|c|c|c|c|c|}
\hline \multicolumn{2}{|c|}{$\begin{array}{c}\text { defect } \\
\text { sub-image }\end{array}$} & $\begin{array}{c}\text { broken } \\
\text { ends }\end{array}$ & crapand & $\begin{array}{c}\text { double } \\
\text { end }\end{array}$ & $\begin{array}{c}\text { double } \\
\text { weft }\end{array}$ & $\begin{array}{c}\text { necked } \\
\text { yarn }\end{array}$ & flush & knees & $\begin{array}{c}\text { weft } \\
\text { crackiness }\end{array}$ \\
\hline \multirow{2}{*}{$\mathrm{LL}$} & $\mathrm{SD}$ & 8.3 & 8.7 & 13.5 & 12.1 & 11.6 & 14.2 & 12.2 & 9.8 \\
\cline { 2 - 12 } & $\mathrm{MD}$ & 66.4 & 66.1 & 75.6 & 73.2 & 73.1 & 84.6 & 78.1 & 63.2 \\
\hline \multirow{2}{*}{$\mathrm{LH}$} & $\mathrm{SD}$ & 2.6 & 2.4 & 2.2 & 4.9 & 4.7 & 3.5 & 4.4 & 4.8 \\
\cline { 2 - 11 } & $\mathrm{MD}$ & 26.1 & 20.8 & 12.9 & 26.9 & 28.1 & 23.2 & 25.3 & 29.1 \\
\hline \multirow{2}{*}{$\mathrm{HL}$} & $\mathrm{SD}$ & 4.5 & 4.8 & 4 & 2.3 & 2.4 & 2.3 & 2.3 & 2.4 \\
\cline { 2 - 10 } & $\mathrm{MD}$ & 26.9 & 28.1 & 23.1 & 11.9 & 13.6 & 12.8 & 12.3 & 15.2 \\
\hline \multirow{2}{*}{ three sub-images } & SD+MD & 134.8 & 130.9 & 131.3 & 131.3 & 133.5 & 140.6 & 134.6 & 124.5 \\
\hline
\end{tabular}

By calculating, it is known, contrast to the mean of the (SD+MD) of normal fabric's three sub-images, that minimum deviation is $13.6 \%$ and maximum $28.3 \%$. According to this, defects can be detected by comparing the (SD+MD) of windows on LL, LH, HL sub-image with the images of normal fabric. In view of the pure cotton grey cloth used in the experiment, finally $5 \%$ was determined as the standard deviation of the three sub-images' (SD+MD). That is to say, after the interesting areas waiting for detection were decomposed on wavelet, LL, LH, and HL three sub-images were got. By measuring the $(\mathrm{SD}+\mathrm{MD})$ of three sub-images which were compared with the means of normal fabric's, deviations were used to detect whether fabrics contain defects or not. [6]

\section{Comparative Experiment}

A roll of cloth was normally detected on a machine, its results were contrasted to the one of artificial detecting as follows:The detecting speed of the system is twice faster than the average one of artificial detecting, close to $60 \mathrm{~m} / \mathrm{min}$; The distribution of measured data is in order, and good in gathering. Because the overlapping parts of the eigenvalue data between normal texture images and defects ones are less, it is convenient for defects detection;

The undetected rate of artificial detection is usually as high as $20 \sim 30 \%$, the detection rate only $70 \%$ or so; while using the detection system referred in this paper, the detection rate of normal fabric is more than $98 \%$, the detection rate of detects can amount to $91 \%$, error-detected rate is $7.3 \%$, undetected rate is $3.5 \%$. So the results of the fabric defect automatic detection system are much better than ones of artificial detection. 


\section{Experimental Conclusions}

A new method that combines the rough detecting by local entropy with the fine detecting by wavelet was used in this experiment. By using it, more than $95 \%$ of normal fabric in the rough-detecting stage by local entropy could be ruled out, only about less than $5 \%$ of defects fabric needed to be finely detected by wavelet. Because in the fine-detecting stage by wavelet, the single adaptive wavelet decomposition was adopted, just after a layer of decomposition, the detection speed could be improved.

As extracting characteristic parameters, this algorithm is not influenced by fabric texture direction, so can adapt the types of fabric and defects better. Its average detection accuracy is $90 \%$ (Un- and error-detected) sample number is 21, the total sample number is 200), it has higher detection effect. The experiment meaningfully explored and boldly tried to find the effective algorithm of one hundred percent detecting fabric defects. [7,8]

\section{References}

[1] A Conci, C B Proenca. A Computer Vision Approach for Textile Inspection. Textile Res. J 2000, 70(1):347-350

[2] L. Q. Li, A Study on Computer-Vision-Based Fabric Defect Automatic Inspection. Shanghai: Donghua University Doctoral Degree Dissertation, 2003.

[3] Z. B. Xu, Y. N. Gong, and X. B. Huang, "Two-Dimensional Wavelet Transform-Based Fabric Defect Inspection,” China Textile University Journal, vol. 26,2, 2000, pp. 10-13.

[4] Z. K. Xu, Z. M. Deng and Y. Zhao, "Wavelet Transform-based Machine Woven Meridian and Parallel Density Measuring,” Wuhan Science and Technology Institute Journal, vol. 19, 2, 2006, pp. 30-33.

[5] TEA JIN KANG, CHANG HOON KIM. KYUNG WI-IAOH. Automatic Recognition of Fabric Weave Patterns by Digital Image Analysis [J].T. R. J.,1999, 69(2):77-83.

[6] W. F. Chen, An Application of Wavelet Analysis to Image Processing. Beijing: Science Press, 2002, pp. 112-120.

[7] Nicola Neretti, Nathan Intrator. An Adaptive Approach To Wavelet Filters Design, IEEE 2002: 317-324

[8] Toshiro Kubota et al. A non-destructive automated defect-detection system for silicon carbide wafers. Machine Vision and Applications, 2003:1- 9. 